\title{
Experimental Study of Stress-Strain Behaviour of Open-Cell Aluminium Foam Sandwich Panel for Automotive Structural Part
}

\author{
Nur Asmawiyah Ibrahim, Muataz Hazza F. Al Hazza, Erry Yulian Triblas Adesta, Nor Amalina \\ Endut and Asyfiq Hanif Asman
}

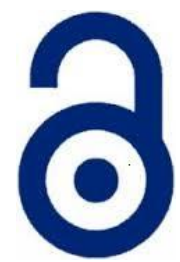

\author{
Received: 25 February 2017 \\ Accepted: 09 June 2017 \\ Published: 27 June 2017 \\ Publisher: Deer Hill Publications \\ (c) 2017 The Author(s) \\ Creative Commons: CC BY 4.0
}

\begin{abstract}
Because of high stiffness and strength to weight ratio, aluminium foam sandwich (AFS) has huge advantage in automotive industries in order to reduce the vehicle's weight which consequently will reduce the fuel consumption. While reducing the weight, AFS must also maintain high strength and durability compared to other competitive materials used which perform same functionalities. AFS had been proved its suitability for industrial application by previous researchers such as in aerospace, automotive and architecture. However, there is still a gap need to be filled in order to expand the use of the AFS in another application. In this paper, the tensile strength of AFS panel made of from aluminium skin sheets and open-cell aluminium foam core with various thicknesses is investigated. To achieve the objectives of the research, experimental work has been conducted. Full factorial of two independent factors: core thickness with two levels and skin thickness with three levels. JMP software (version 11) has been used to analyse the data. Experimental work was done using universal testing machine. The stress-strain behaviour was analysed. The result shows that the effect of skin to core ratio is significant on the stress-strain behaviour.
\end{abstract}

Keywords: Aluminium foam sandwich, design of experiment, stress-strain curve, tensile strength, open-cell.

\section{INTRODUCTION}

In the past few years, metallic foams have gained their reputations in the industries all around the world. The main factor that leads to the further development of this type of material is caused by the demand of lightweight constructions such as automotive and ship parts. One of the most frequently used metallic foam is the aluminium foam. Because of its low-cost manufacturing process and more convenience, aluminium foam tends to be chosen more compared to other type of metallic foam. The manufacturing process of the aluminium foam consist of two routes; PM and LM routes. LM routes used melting aluminium that then foamed to be aluminium foam. PM routes on the other hand, used powder metallurgy in order to produce the aluminium foam intended [1].

The further development of the aluminium foam is aluminium foam sandwich (AFS). It is an advanced material technology that consist of highly porous aluminium foam core that sandwiched by two aluminium sheets acting as the faces on the both sides of the core [2]. Applications of AFS have been widely proposed on several sectors and industries including ship building [3], aircraft and railway industries [4], automotive parts [5] and several other constructions industries. AFS have several advantageous to offer compared to dense aluminium metal. AFS more stiff when compared to the dense aluminium sheet with the same weight [6]. Moreover, when compared to bare aluminium foam, the metal sheets of the AFS that acting as faces allows it bear greater tensile load and reduced the deformation of the core. Bare aluminium foam has low endurance to tension and the fractures can occur faster compared to AFS. The aluminium foam that has been sandwiched together with the metal sheets also can avoid the occurrence of corrosion and surface damage. Figure 1 show an example [5] of using AFS in manufacturing a novel lifting arm supporting a repair platform mounted on a small lorry

N. A. Ibrahim, H. F. H. Muataz 凶, E. Y. T. Adesta, N. A. Endut and A. H. Asman

Department of Manufacturing and Materials Engineering

International Islamic University Malaysia

PO Box 10, 50728 Kuala Lumpur, Malaysia

E-mail: muataz@iium.edu.my

Reference: Ibrahim, N. A., Hazza, M. H. F., Adesta, E. Y. T., Endut, N. A., and Asman, A. H. (2017). Experimental Study of StressStrain Behaviour of Open-Cell Aluminium Foam Sandwich Panel for Automotive Structural Part. International Journal of Engineering Materials and Manufacture, 2(2), 25-30. 


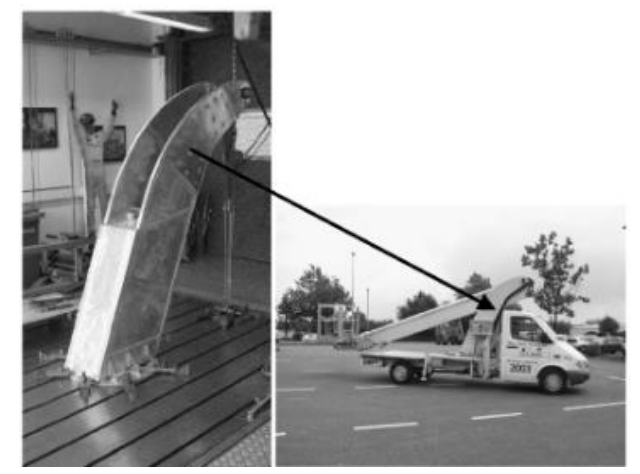

Figure 1: Lifting arm made from AFS sandwich panels [5]

However, the main intention of applications of AFS is to reduce weight of the respective construction parts. In order to overcome the minimum level of energy resources, such as fuel, some actions must be done. Energy resources, especially the non-renewable type like petroleum and natural gas need to be controlled and minimised in terms of usage. In automotive industries, to be exact, designs of the parts have to consider the reduction of the mass. Reduced in mass can improve the performance and lower the usage of fuel. An extra $100 \mathrm{~kg}$ in weight alone would results in $0.72 \mathrm{l} / 100 \mathrm{~km}$ increase in fuel consumption for hybrid-electric vehicles (HEV), and 0.77 l/100 km increase in fuel consumption for internal combustion engine vehicles (ICEV). Weight is proved to have a significant factor of fuel consumption when both weight and power are evaluated as fuel consumption factor [7]. As the increase of the fuel's price from time to time, the reductions of automotive weight may be the solutions to the problems of shortage in energy resources that we are facing nowadays. It also will benefit us in terms of economic for long term runs.

In order to be used as substitute materials, AFS have to undergo several tests and experiments to prove that it is qualified to replace the currently used material. The AFS supposed to have the same or better properties when compared to the conventional material used for the past constructions. In terms of mechanical properties, for example, AFS should possess the ability of withstanding high load and deform at a minimum level. It also needs to have a high durability in order to perform well as the substitution material in the constructions of automotive parts.

\section{METHODOLOGY}

In this research, twelve specimens of AFS were tested under tensile test for determining the tensile stress/strain curve. The specimens are designed so that an aluminium foam acting as the core of the sandwich and attached in between of aluminium sheet grade 6061. Based on the foams supplied, two levels of thickness of the aluminium foam were used which is 6.35 and $10 \mathrm{~mm}$. While the level for aluminium skin thickness were $0.4 \mathrm{~mm}, 0.6 \mathrm{~mm}$ and $0.8 \mathrm{~mm}$. The design of experiments of input combination was developed in JMP statistical analysis software and six numbers of runs with different input combination had been created. Table 1 explained more regarding the number of runs required.

The process begins by constructing the 'dog-bone' shape specimens of AFS. The aluminium foams and the aluminium sheets will be cut using the EDM Wire Cut Machine to produce the intended shapes. Then, the foams will be glued together using the Araldite Rapid Steel Epoxy with the aluminium sheets on the both side to become the AFS as shown in Figure 2. After that, the specimen was undergo tensile test using INSTRON 5582 Universal Testing Machine, the specimen was clamped at both and pull upward with one side remain fixed. The pulling process continued at a constant speed of $1.67 \mathrm{~mm} / \mathrm{min}$ until the specimen fully brake. Figure 3 shows the setup of the specimen and the specimen that is fully brake. As the load applied to the specimens, a stress-strain curve will be constructed using the BLUEHILL software.

Table 1: Design of experiment for AFS

\begin{tabular}{ccc}
\hline \multirow{2}{*}{ No. of run } & \multicolumn{2}{c}{ Input parameters } \\
\cline { 2 - 3 } & Core thickness & Skin thickness \\
\hline 1 & 6.35 & 0.4 \\
2 & 6.35 & 0.6 \\
3 & 6.35 & 0.8 \\
4 & 10.0 & 0.4 \\
5 & 10.0 & 0.6 \\
6 & 10.0 & 0.8 \\
\hline
\end{tabular}




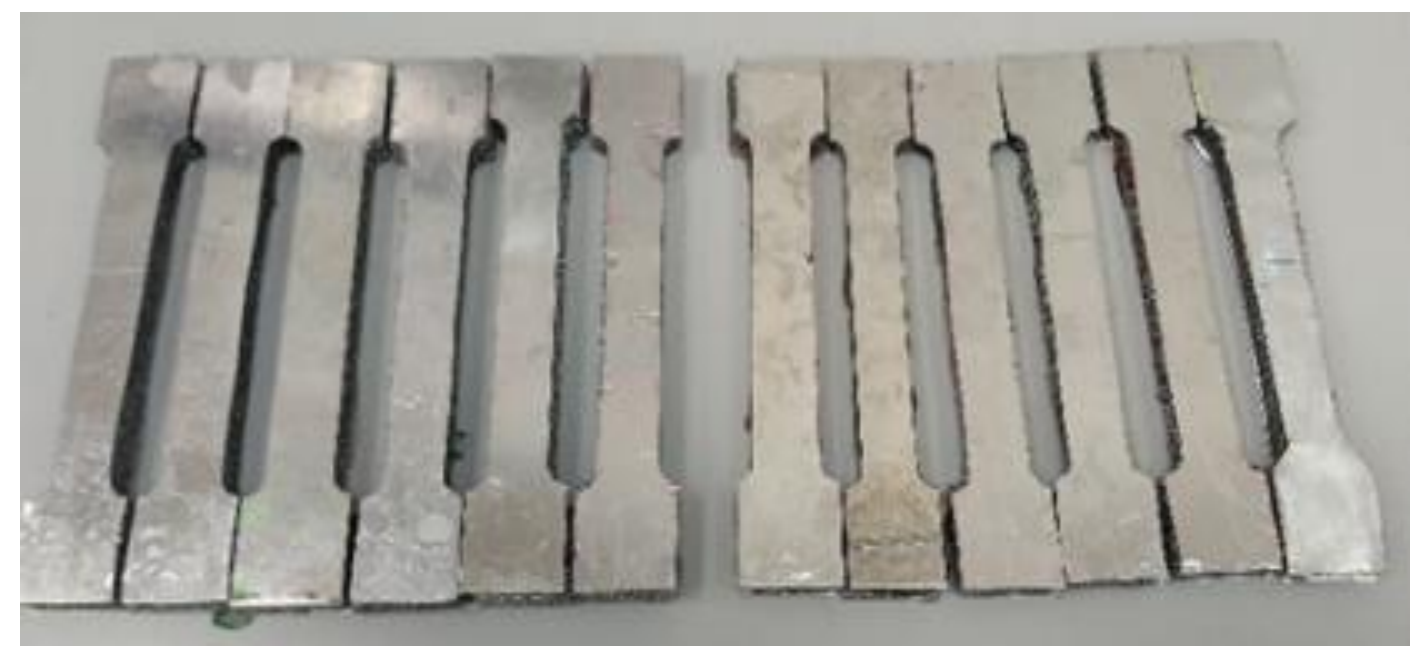

Figure 2: ‘Dog-bone’ AFS specimens

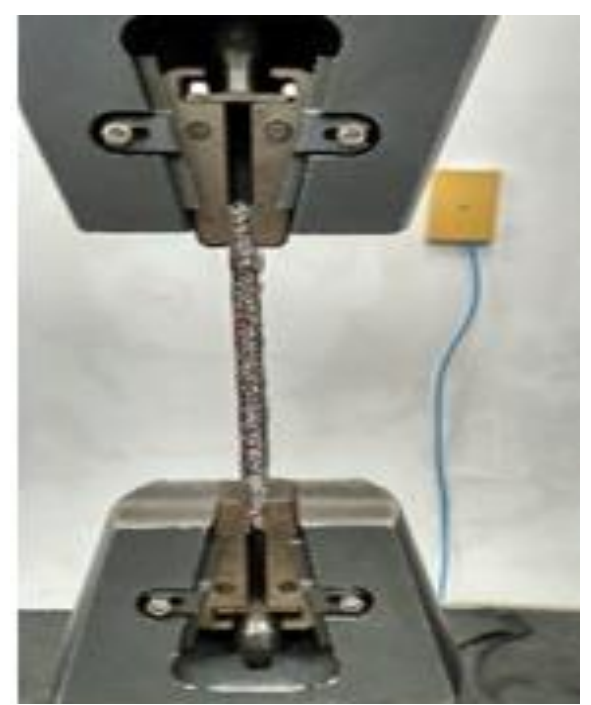

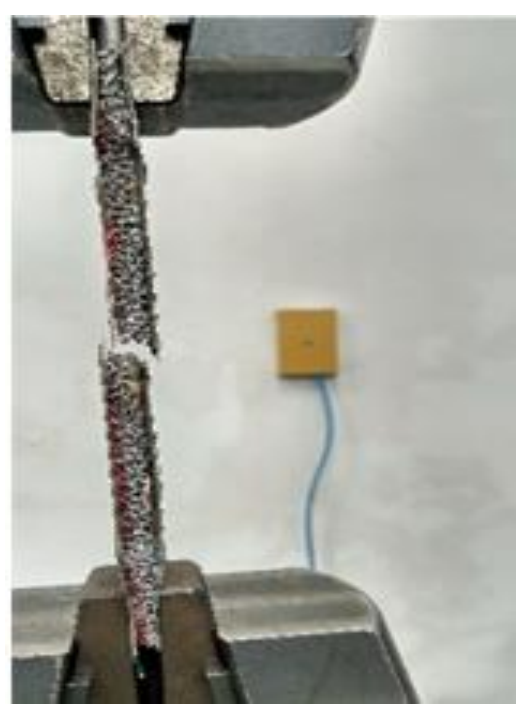

b

Figure 3: (a) Setup of the specimen on the tester machine, (b) The broken specimen.

\section{PROCESS DEVELOPMENTS}

\subsection{Fabrication of aluminium foam sandwich}

To investigate the stress/strain curve of aluminium foam sandwich (AFS), first the sandwich panels were fabricated. Before fabricating the AFS, aluminium sheet and foam were cut into dog-bone shape as referred to standard. The sheet and foam were cut using electrical discharge machine (wire cut) but for thickness less than $0.4 \mathrm{~mm}$ need to be cut by scroll saw. In this process, it is found that EDM wire cut cannot support the specimen that were too thin which will cause nonlinear edge finishing.

The aluminium used to produce foam was aluminium grade 6061. The bulk density and porosity of the foam was $0.2 \mathrm{~g} / \mathrm{cm}^{3}$ and $93 \%$ respectively. To have the connection between the skin and core, the mixture of epoxy resin and 
hardener with ratio 2:1 was layered in between the aluminium sheets and aluminium foam. According to ASTM standard of C393/C393M, the stable ratio for designing the specimen for sandwich structure is as the equation below:

$\begin{array}{ll} & t \\ t: \text { skin thickness } & \frac{t}{c} \leq \sim 0.10 \\ c: \text { core thickness } & \end{array}$

\subsection{Selection of testing method and input variables}

The mechanical testing method used in this research in order to determine the mechanical behaviour of stress/strain curve of AFS was tensile test using Universal INSTRON testing machine. The test was conducted under the velocity control of constant $1.67 \mathrm{~mm} / \mathrm{min}$. For having the more reliable and accurate data, the test was repeated.

The first trial of six run was conducted with the velocity constant of $1.67 \mathrm{~mm} / \mathrm{min}$ and the output set was the tensile stress/strain curve and the maximum load AFS can withstand. The thickness of foams were $6.35 \mathrm{~mm}$ and $10 \mathrm{~mm}$, while the thickness of sheets were $0.4 \mathrm{~mm}, 0.6 \mathrm{~mm}$ and $0.8 \mathrm{~mm}$. The result and graph were extracted and tabulated and show in the result and discussion part. For the second trial, the six number of run with same input parameters combination as first trial were conducted using same machine set up. Result for experimental were analysed based on the previous researchers. Next, the work was continued with the data analysis. The pattern and value of maximum tensile stress-stress curve when maximum loaded and break were analysed. It is important to know the maximum load AFS can withstand for determining the suitable application of the AFS parameter. After that, desirability function of the model was developed in JMP statistical analysis in order to have stable and balance result.

\section{EXPERIMENTS AND MEASUREMENT}

The experiments were designed using full factorial of two independent factors: core thickness with two levels (6.32 and $10 \mathrm{~mm})$ and skin thickness with three levels $(0.4,0.6$, and 0.8$) \mathrm{mm}$. Therefore, total six treatments have been conducted. The core and skin thickness considered the ratio not to be more than 0.1 based on ASTM standard of C393/C393M. Each treatment has been conducted with two replications to increase the reliability of the test. The experiment was designed in order to determine the tensile stress-strain of AFS and how sandwich structure affects the curve. The responses were analysed using desirability function in JMP software.

The experimental work first conducted by fabrication of the AFS. Then the test was proceeding by gripping the both side of dog-bone AFS specimen to the tensile test machine. The Universal INSTRON testing machine was connected to the computer which contained Blue Hill software for developing the stress-strain curve of AFS. After the specimen gripped to testing machine tightly, the tensile test was started by clicking the start icon in the Blue Hill software and undergoes tension until the specimen break. The results were extracted from the Blue Hill software for analysing process.

\section{RESULTS AND DISCUSSIONS}

The experimental results were analysed using desirability function in JMP statistical analysis software. The stress strain curve for the six runs have been concluded in Table 2 for each individual run. Table 3 concluded the results for the tensile test of AFS for 6 runs. The tests were repeated in order to get more accurate result. The solid line shows the stress-strain curve obtained from the tensile tests on dog-bone specimens of AFS. There two stress-strain curve for each run which represent the result for first and second trial respectively. Stress was calculated by dividing the force over the cross-sectional area for both skins and core. Based on the graphs tabulated below, the stress value shows the almost constant result for both first and second trial with the differences was $4 \%$ to $20 \%$. The highest stress obtained was for run 3 for combination of skins and core thickness of $0.8 \mathrm{~mm}$ and $6.35 \mathrm{~mm}$ respectively. While the lowest value of stress ( $\mathrm{MPa}$ ) was for run 4 for combination of $10 \mathrm{~mm}$ core and $0.4 \mathrm{~mm}$ skins thickness.

As expected, based on the pattern of collected data, it can be see that as the skin to core ratio increase, the stress, strain and maximum load also increase. This can be support by previous research done by Shetty and Han also mentioned the effect of skin to core ratio [8]. They also found out that as the skin to core ratio increase, the tensile stress also experience the increases. 
Table 2: Tensile stress-strain curve for AFS

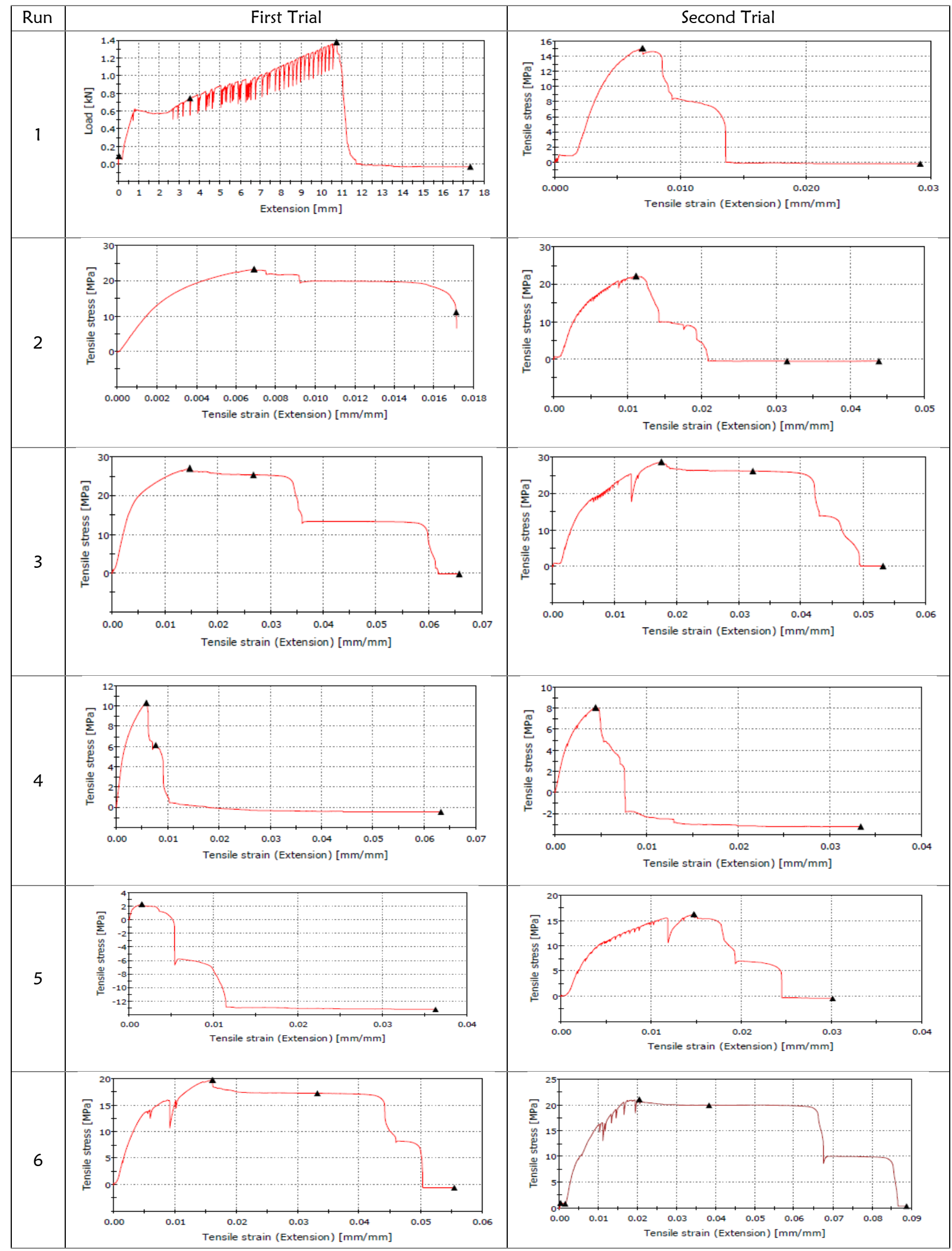


Table 3: Data compilation of tensile test on AFS for first and second trial

\begin{tabular}{cccccccc}
\hline Run & $\begin{array}{c}\text { Skin to } \\
\text { core ratio }\end{array}$ & $\begin{array}{c}\text { Maximum } \\
\text { Stress }(\mathrm{MPa})\end{array}$ & $\begin{array}{c}\text { Maximum strain } \\
(\mathrm{mm} / \mathrm{mm})\end{array}$ & $\begin{array}{c}\text { Maximum } \\
\text { Load }(\mathrm{N})\end{array}$ & $\begin{array}{c}\text { Maximum } \\
\text { Stress }(\mathrm{MPa})\end{array}$ & $\begin{array}{c}\text { Maximum strain } \\
(\mathrm{mm} / \mathrm{mm})\end{array}$ & $\begin{array}{c}\text { Maximum } \\
\text { Load (N) }\end{array}$ \\
\hline 1 & 0.062 & 12.854 & 0.002 & 1378.61 & 15.045 & 0.007 & 1613.63 \\
2 & 0.094 & 23.247 & 0.007 & 2632.73 & 22.16 & 0.011 & 2509.64 \\
3 & 0.126 & 26.998 & 0.014 & 3219.56 & 28.601 & 0.018 & 3410.70 \\
4 & 0.062 & 10.328 & 0.006 & 1673.00 & 8.059 & 0.004 & 1305.60 \\
5 & 0.094 & 15.482 & 0.011 & 2553.36 & 16.246 & 0.014 & 2729.25 \\
6 & 0.126 & 19.734 & 0.016 & 3433.72 & 21.104 & 0.020 & 3672.00 \\
\hline
\end{tabular}

\section{CONCLUSIONS}

In this study, specimens of AFS with two levels of core thickness and three levels of face thickness have been fabricated. Next, the specimens have been undergone through tensile test were the stress-strain behaviour was analysed. Based on this experimental study of AFS the following conclusions are drawn.

- Increase in the ratio of face-to-core thickness will increase the tensile modulus value of the specimen.

- Increase in face thickness will increase the tensile modulus value if the core thickness kept constant.

- Increase in core thickness will decrease the tensile modulus value if the face thickness kept constant.

- In order to replace the aluminium alloy car parts, the design of the AFS need to be modified so that it will become stronger.

\section{ACKNOWLEDGEMENT}

This research was funded by Ministry of Higher Education Malaysia under Research Grant FRCS15-247-0488. The authors also acknowledged the support from technical staff from Manufacturing and Material Engineering department for the support in carrying out the research work.

\section{REFERENCES}

1. Kammer, C. (1999). Aluminum foam. TALAT Lecture 1410, European Aluminium Association, 1-24.

2. Banhart, J., \& Seeliger, H. W. (2012). Recent trends in Aluminium foam sandwich technology. Advanced Engineering Materials, 14(12), 1082-1087.

3. Banhart, J., Schmoll, C., \& Neumann, U. (1998). Light-weight aluminium foam structures for ships. In Proceedings of the Conference on Materials in Oceanic Environment, 55-63.

4. Yu, C. J., Eifert, H, Banhart, J., and Baumeister, J. (1998). Metal foaming by a powder metallurgical method: production, properties and applications, Materials Research Innovations, 2, 181-188.

5. Banhart, J. (2005). Aluminium foams for lighter vehicles. International Journal of vehicle design, 37 (2-3), 114 125.

6. Ashby, M. F., Evans, T., Fleck, N. A., Hutchinson, J. W., Wadley, H. N. G., \& Gibson, L. J. (2000). Metal foams: a design guide. Elsevier.

7. Reynolds, C., \& Kandlikar, M. (2007). How hybrid-electric vehicles are different from conventional vehicles: the effect of weight and power on fuel consumption. Environmental Research Letters, 2(1), 014003.

8. Shetty, R., \& Han, C. D. (1978). A study of sandwich foam coextrusion. Journal of Applied Polymer Science, 22(9), 2573-2584. 